\title{
Revisão sistemática das características dos homicídios contra a população LGBT
}

\author{
Systematic review of the characteristics of LGBT homicides
}

Wallace Góes Mendes (http://orcid.org/0000-0002-7852-7334) ${ }^{1}$

Marco José de Oliveira Duarte (https://orcid.org/0000-0002-6395-1941) ${ }^{2}$

Carlos Augusto Ferreira de Andrade (https://orcid.org/0000-0002-0098-4957) ${ }^{3}$

Cosme Marcelo Furtado Passos da Silva (http://orcid.org/0000-0001-7789-1671) ${ }^{3}$

\footnotetext{
${ }^{1}$ Escola Superior de Ciências da Saúde, Universidade do Estado do Amazonas. Av. Carvalho Leal 1777, Cachoeirinha. 69065-001 Manaus AM Brasil. wgmendes@uea.edu.br ${ }^{2}$ Faculdade de Serviço Social, Universidade Federal de Juiz de Fora. Juiz de Fora MG Brasil.

${ }^{3}$ Departamento de Epidemiologia e Métodos Quantitativos em Saúde, Escola Nacional de Saúde Pública Sergio Arouca, Fiocruz. Rio de Janeiro RJ Brasil.
}

\begin{abstract}
The lesbian, gay, bisexual and transgender (LGBT) population has long been excluded, a reality produced by social marginalization, which is still present in today's society. This article aims to present a quantitative profile of LGBT homicides, focusing on the crimes, victims, and perpetrators. We conducted a systematic review of quantitative studies on LGBT homicide using the following databases: PubMed Central (Medline), Latin American and Caribbean Center for Health Sciences Information (LILACS), Embase (Elsevier), Scopus (Elsevier), the Virtual Health Library (BVS), and APA PsycNet. The searches were run using terms taken from the Medical Subject Headings (MESHs) and Health Sciences Descriptors (DeCS-BVS). Sixteen studies were included. Homicides tended to involve a single victim and single perpetrator and occur at the victim's residence or in public locations. Victims were more likely to be older than the perpetrator and offenders were usually unknown to the victim. Transgender people were the most affected group and most of the victims in this group were aged under 30 years. The findings of this review confirm that LGBT homicides may be considered "hate crimes" and that victims are generally killed with firearms or non-firearms, beaten to death or suffocated.

Key words Sexual and gender minorities, Homicide, Homophobia, Systematic review
\end{abstract}

Resumo A população de Lésbicas, Gays, Bissexuais, Travestis e Transexuais (LGBT) há tempo mostra-se excluída da sociedade. Uma realidade oriunda da marginalização ainda presente nos dias de hoje. O objetivo deste artigo é descrever o perfil quantitativo de homicídios contra a população LGBT quanto às características dos crimes, das vítimas e dos autores. Revisão sistemática, incluindo estudos quantitativos sobre homicídios de LGBT. As bases das pesquisas foram: Pubmed Central (Medline); Literatura Latino-Americana e do Caribe em Ciências da Saúde (LILACS); Embase, (Elsevier); Scopus (Elsevier), Biblioteca Virtual em Saúde (BVS) e PsyNET (American Psychological Association - APA) com termos MESH selecionados. Protocolo do PROSPERO: CRD42016053977. Dezesseis estudos foram incluídos. Os homicídios tendem a envolver uma vitima e um autor, que ocorrem na residência da vítima ou via pública. A vítima geralmente é mais idosa do que o autor do crime, normalmente desconhecido pela vítima. Os transgêneros são os LGBT mais acometidos e, em geral, são jovens com menos de 30 anos. Esta revisão confirma que esses homicídios podem ser considerados "crimes de ódio", em que esses indivíduos, em geral, são vitimados por armas de fogo, armas brancas, espancados ou asfixiados até a morte.

Palavras-chave Minorias sexuais e de gênero, Homicídio, Homofobia, Revisão sistemática 


\section{Introdução}

A identidade de gênero e orientação sexual têm sido objetos de investigações no intuito de trazer à baila discussões, às quais possam minimizar as intolerâncias em relação à população LGBT. Contudo, há poucos estudos que discutem a violência letal na população de LGBT em periódicos internacionais, mais especificamente o homicídio, que hoje é um grave problema de saúde pública ${ }^{1}$. Um termo recente muito comum na literatura internacional é transgênero, que tem sido usado para identificar pessoas travestis, mulheres e homens transexuais e outros que não se enquadram ao binarismo de gênero, mas também para pessoas intersexuais e não-binárias².

Apesar do conceito de homofobia significar uma manifestação arbitrária, que consiste em designar o outro como contrário, inferior ou anormal ${ }^{3}$ restringindo-se as identidades afetivo-sexuais de lésbicas, gays e bissexuais, os assim denominados "crimes de ódio" representam também as manifestações de discriminação, medo ou ódio com base na identidade de gênero, configurando-se como transfobia. Contudo, o neologismo usado atualmente pelo movimento social de LGBT internacional é intitulado como LGBTfobia, que tem englobado no referido termo, a homofobia, a lesbofobia, a bifobia e a transfobia, demarcando que as vítimas são escolhidas porque são consideradas ou percebidas como LGBT ${ }^{4,5}$.

Em 2019, no panorama internacional ainda haviam 55 países sem proteção contra a discriminação com base na orientação sexual e identidade de gênero. Destes países, há dois países (Egito e Iraque) nos quais ser LGBT é crime; em 30 punem os LGBT com até oito anos de prisão; 26 punem os LGBT com dez anos até prisão perpétua e 6 países com pena de morte efetiva (Arábia Saudita, Iêmen, Iran, Nigéria, Somália e Sudão). Vale salientar que em vários desses países as leis são baseadas na religião, aliadas ao código civil ${ }^{6}$.

Dentre os países que têm reconhecimento dos direitos dos LGBT, em 123 países os atos sexuais consensuais entre pessoas adultas do mesmo sexo são permitidas; em 58 é garantido o casamento (27 países) ou união civil (31 países); 27 países reconhecem as famílias homoparentais e permitem a adoção conjunta por casais do mesmo sexo. Revelando, com isso, que em muitos destes países ainda não se tem legislações sobre esses temas e, particularmente, somente 36 países garantirem direito à população de transgêneros ${ }^{6,7}$.

Dos relatos de homicídios de LGBT no mundo, a Transgender Europe (TGEU), que é uma rede de diferentes organizações, registrou a existência de 3.314 homicídios de transgêneros em 74 países no período de janeiro de 2008 a setembro de 2019 , sendo que $61 \%$ dos vitimados trabalhavam como profissionais do sexo. Nos Estados Unidos da América, 90\% dos assassinatos foram de transgêneros negras ou nativas americanas. Na França, Itália, Portugal e Espanha, 65\% das vítimas eram provenientes África e da América Latina. De outubro de 2018 a setembro de 2019, o Brasil apresentou o maior quantidade de mortes de transgêneros com 130 mortes, seguido do México com 63 mortes e dos Estados Unidos da América com 30 mortes, totalizando 331 casos reportados em todo o mundo8. É importante destacar que não há informações oficiais acerca de homicídios de gays e lésbicas por instituições internacionais sociais e de saúde.

Até o momento da coleta de dados poderíamos afirmar que haviam poucos estudos internacionais, que examinavam a prevalência e a dinâmica dos homicídios da população de LGBT, reduzindo sua utilidade e generalização. Isso ocorre devido à subnotificação dos casos, pois os homicídios, em geral, não possuem evidências de homofobia. Sendo assim, fica difícil comprovar a presença de homofobia nesses crimes, porque normalmente o autor não é conhecido ou a vítima não era reconhecida como $\mathrm{LGBT}^{9,10}$. Além disso, os sistemas penais pelo mundo ainda não estão preparados para identificar, investigar e julgar tais crimes ${ }^{6,8,11}$.

Este estudo se propõem a realizar uma revisão sistemática dos crimes, das vítimas e dos autores de homicídios contra a população de LGBT, apresentando um perfil quantitativo desses homicídios. Trata-se, portanto, de uma pesquisa com a qual se pretende dar visibilidade e contribuir para o debate nos estudos sobre o tema na área de Saúde Coletiva e, em particular, na análise desses tipos de crimes, impulsionar as demandas de LGBT frente às lacunas no campo das políticas públicas voltadas à proteção dessa população, que ainda se encontra exposta a uma vulnerabilidade insuportável e desumana com seus corpos e vidas precárias ${ }^{12}$, mesmo em países nos quais não há criminalização das dissidências sexuais e de gênero ${ }^{13}$.

\section{Métodos}

Realizou-se uma revisão sistemática da literatura, sendo planejada e executada de acordo com um protocolo registrado no dia 22/12/2016, atualiza- 
do no dia 27/07/2020 e publicado na base International Prospective Register of Systematic Reviews (PROSPERO), com o registro CRD42016053977. O protocolo encontra-se disponível no link $h t$ tps://www.crd.york.ac.uk/prospero/display_record. asp? ID $=C R D 42016053977$. As etapas de realização do estudo e a redação do artigo foram orientadas pelas recomendações do documento Preferred Reporting Items for Systematic Reviews and Meta-Analyses (PRISMA) ${ }^{14}$.

Foi utilizada a estratégia qualitativa PEO (Paciente, Exposição e Desfecho - "Outcome") adaptada para um estudo quantitativo, necessária para a busca de evidências ${ }^{15,16}$. Considerou-se a população de LGBT do mundo como "P", ser um indivíduo LGBT como " $\mathrm{E}$ " e o desfecho foi "morte por homicídio" como "O".

Foram incluídos apenas estudos epidemiológicos com desenhos observacionais quantitativos descritivos (seccionais e ecológicos), que descrevem homicídios de LGBT, independentemente se houve motivação homofóbica ou não. Foram selecionados artigos e outras publicações científicas, sem restrição de ano e de idioma, incluindo os estudos da "literatura cinzenta", que são publicações não-convencionais (sem revisão por pares) e comerciais.

O primeiro critério de exclusão foram os suicídios de LGBT, pois o objeto de estudo são apenas os homicídios de LGBT. O segundo foram os estudos que limitam a população em apenas um grupo etário: jovens, adultos ou idosos, pois retratariam os homicídios apenas numa parte da população, o que não é o interesse desse estudo. O terceiro foram os estudos de homicídios de LGBT com abordagem exclusivamente qualitativa, pois o enfoque é de apresentar o perfil quantitativo dos homicídios.

A pesquisa de artigos e outras publicação científicas foi realizada nas bases de dados Pubmed Central (Medline); Centro Latino-Americano e do Caribe de Informação em Ciências da Saúde (LILACS); Embase, (Elsevier); Scopus (Elsevier) e PsyNET (American Psychological Association - APA). A última busca para atualização dos dados foi realizada no dia 30 de junho de 2019.

A estratégia de busca realizada com auxílio de uma bibliotecária especializada na elaboração de revisões sistemáticas (MFMM), onde selecionou-se descritores retirados do Medical Subject Headings (MeSH - Pubmed) e Descritores de Ciências de Saúde (DeCS - BVS $)^{17}$, nos idiomas inglês, português e espanhol e consistiram em: "homophobia", "sexism", "bisexuality", "homose- xuality", "gay”, "lesbian”, “LGBT", “queer”, "transgender persons", "transsexualism", "transvestism", "crime", "criminology", "homicide", "murder" $e$ "victims". Salienta-se que o termo "transfobia" não existe no DeCS - BVS, logo este está incluso nos demais termos. Devido ao grande acervo disponíveis das bases de dados foram utilizados os limites de tipo de publicação científica (artigos, anais de congressos, pesquisa curta, comunicação curta, relatórios, dissertações e teses). Além da busca sistemática nas bases de dados eletrônicas selecionadas também foram realizadas buscas na literatura cinzenta ${ }^{18}$, mais especificamente nos websites da Biblioteca Digital Brasileira de Teses e Dissertações (BDTD), Google Scholar (Internacional), Open Grey (Europa) e National Technical Information Service (Estados Unidos). Ainda foram pesquisadas as referências cruzadas das publicações pré-selecionadas, a fim de identificar novas publicações de relevância para esta revisão sistemática.

$\mathrm{Na}$ seleção dos estudos foi realizada uma busca ampla nas bases de dados eletrônicas existentes, algo que possibilitou obter todos os estudos para inclusão nesta revisão sistemática. Assim, os artigos e as outras publicações científicas selecionadas foram inseridos no programa Zotero, versão 5.0.88, sendo removidas as duplicatas, que formaram o Conjunto 1 e enviado aos dois primeiros autores, que foram os responsáveis pela seleção das publicações por meio dos títulos e resumos, utilizando respostas binárias ("sim" ou "não"). As publicações com decisões conflitantes foram submetidas ao quarto autor, que decidiu sobre a permanência ou remoção. As publicações selecionadas formaram o Conjunto 2, sendo obtidos com o texto completo para a leitura e análises detalhadas pelos dois primeiros autores, que removeram as publicações usando os critérios de exclusão. As permanências das publicações discordantes foram decididas pelo quarto autor. Os textos restantes formaram o Conjunto 3 , que foram avaliados pelos dois primeiros autores, onde as informações coletadas foram: título, autores, ano, local, período, tamanho da amostra ou população, identidade de gênero ou orientação sexual das vítimas, fonte dos dados e principais resultados, sendo revisadas pelo terceiro e quarto autor. Os estudos encontrados na literatura cinzenta e referências cruzadas foram incluídos nos Conjuntos, passando pelas mesmas etapas de seleção dos outros estudos.

Para avaliar a qualidade dos estudos incluídos foi utilizado o Guidelines for Critically Appraising Studies of Prevalence or Incidence of a Health Pro- 
blem ou "Loney 1998"19, que é composto de oito perguntas sobre adequação e qualidade do estudo, relacionadas à validade dos métodos, interpretação e aplicabilidade dos resultados. A avaliação foi realizada independentemente por dois primeiros autores e a concordância entre eles foi de $87,5 \%$. As avaliações discordantes foram discutidas até que se obtivesse consenso com o terceiro e quarto autor.

Os dados absolutos, médias e porcentagens foram extraídos dos textos, sendo que as médias utilizadas foram ponderada, que leva em consideração o tamanho amostral de cada estudo. Assim, quanto maior a amostra do estudo maior será o peso de seus resultados.

\section{Resultados}

Foram encontrados 702 registros nesta revisão sistemática, sendo 650 registros identificados de base de dados eletrônicas (busca sistemática - BS) e 52 registros identificados em outras fontes (literatura cinzenta - LC). Após a retirada dos registros duplicados resultou em 356 resumos da busca nas bases eletrônicas de dados tradicionais e 52 resumos da literatura cinzenta, totalizando 408 registros potencialmente relevantes para leitura de títulos e resumos. Após esta etapa, 374 estudos foram excluídos, restando 34 publicações para a leitura completa. Destes, 18 estudos foram excluídos por não atenderem os critérios de elegibilidade, restando ao final 16 estudos. Os motivos das exclusões das publicações foram: abordagem unicamente qualitativa (textos de discussão e/ou reflexão da temática); textos não considerados como publicação científica (matérias de jornais ou revistas eletrônicas); relatórios já publicados como artigos científicos; abordagem de apenas uma faixa etária das vítimas e/ou autores do crime; crimes praticados por parceiros íntimos e crimes não letais. O processo de seleção está detalhado na Figura 1.

Os principais resultados apresentados nos estudos, que fazem parte dessa revisão sistemática encontram-se descritos na Tabela 1.

Com relação ao tipo de estudo, só foram encontrados estudos seccionais e ecológicos. Foram selecionados dez estudos, que descrevem características dos atos criminosos, das vítimas e dos autores ${ }^{9,10,20-27}$; cinco estudos que descrevem características dos crimes e das vítimas ${ }^{11,28-31}$ e um estudo descreve apenas características das vítimas $^{32}$. Dos estudos selecionados, 14 foram ecológicos, mais especificamente de séries tem- porais $^{9,10,20-31}$ e dois estudos seccionais ${ }^{11,32}$. Foram encontrados estudos sobre homicídios de LGBT em seis países, sendo seis estudos dos Estados Unidos da América ${ }^{9,10,22,23,28,32}$, três do Brasil ${ }^{11,25,29}$, três do México ${ }^{21,30,31}$, dois da Austrália ${ }^{24,27}$, um da Itália $^{26}$ e um da Inglaterra/Pais de Gales ${ }^{20}$, entre os quais há heterogeneidade de culturas e fatores contextuais de diferentes continentes.

A revisão sistemática incluiu 2.921 homicídios de LGBT, tendo o mínimo de 20 homicí$\operatorname{dios}^{26}$ e o máximo de 945 mortes ${ }^{9}$, ressaltando que poucos estudos relatam claramente que os homicídios foram causados por motivação homofóbica. O período de estudo compreendido foi de $u^{11,32}$ a trinta anos ${ }^{22}$.

Apesar de terem sido pesquisados estudos epidemiológicos em todos os idiomas, porém foram encontrados apenas estudos em inglês, português e espanhol, sendo onze estudos em inglês ${ }^{9,10,20,22-24,26-28,30,32}$, três em português ${ }^{11,25,29}$ e dois em espanhol ${ }^{21,31}$, totalizando 16 estudos $^{9-11,20-32}$.

Quanto às técnicas estatísticas empregadas pelos estudos selecionados na apresentação dos resultados, os dezesseis estudos utilizaram a Estatística Descritiva ${ }^{9-11,20-32}$; três estudos aplicaram a Regressão Logística ${ }^{9,10,23}$; dois utilizaram o Teste Exato de Fisher ${ }^{22,28}$; um estudo usou o Teste Quiquadrado $\left(c^{2}\right)^{9}$ e um estudo utilizou o Teste Mann-Whitney ${ }^{28}$.

Os dados encontrados nas publicações sobre os homicídios desta revisão sistemática foram coletados pelos autores destas publicações científicas, sendo que alguns tentaram identificar nas fontes se haviam evidências de homofobia. Todavia, em geral, é difícil afirmar se essa informação esteja correta, principalmente porque na maioria dos crimes não se conhece o autor do homicídio. Esses dados são oriundos de relatórios governamentais, Organizações Não Governamentais (ONGs) ou coletados por ativistas individualmente. Os dados, em geral, são provenientes de artigos de jornais, registros policiais, registros de óbitos e buscas na webpage, detalhados abaixo em relação às caraterísticas e locais dos de crimes, das vítimas e dos seus autores.

\section{Crimes}

Quanto ao local de ocorrência do crime, as residências das vítimas e as vias públicas foram os lugares mais comuns. Nas residências das vítimas, os crimes variaram de $34,3 \%{ }^{9}$ a $64,0 \%{ }^{20}$, com média de 40,5\% em dez estudos ${ }^{9,20-27,31}$. Nas vias públicas, a variação foi de $16,0 \%{ }^{20}$ a $49,0 \%{ }^{21}$,

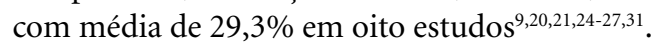




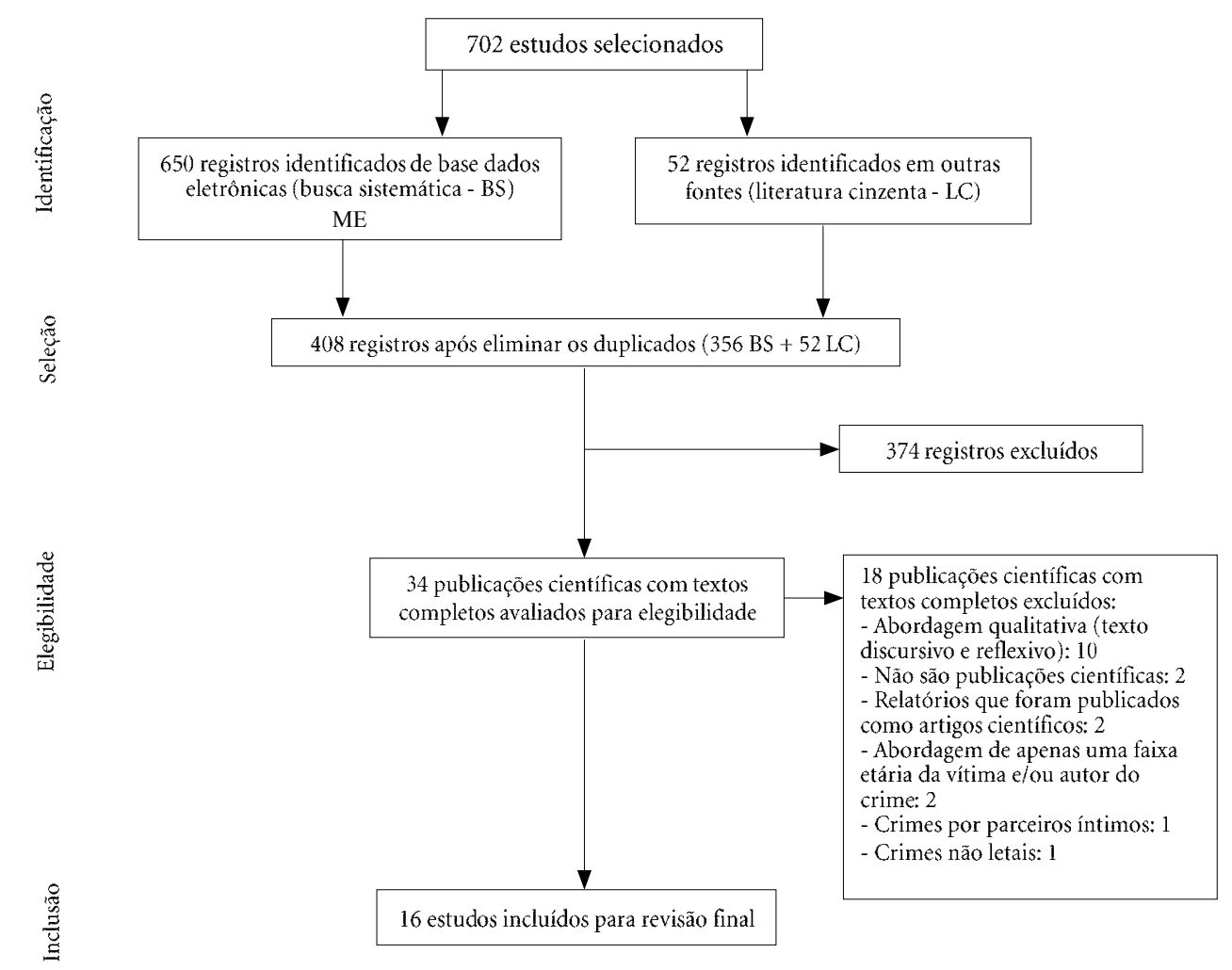

Figura 1. Fluxograma do estudo.

Fonte: Elaborado pelos autores, de acordo com as recomendações do documento PRIMA.

No que se refere à existência de algum tipo de relação da vítima e o posssível autor do homicídio, os crimes realizados por amigos ou conhecidos das vítimas variaram de $24,8 \%{ }^{9}$ a $65,3 \%{ }^{10}$, com média de 32,0\% em oito estudos ${ }^{9-11,21,23,24,26,27}$.

A respeito do meio empregado na causa da morte (causa mortis), o esfaqueamento, o espancamento e as armas de fogo foram as formas mais comuns de acometimento, todavia é frequente ocorrer asfixia, estrangulamento, pauladas, pedradas, carbonização e etc. O tipo de arma branca mais usada no esfaqueamento foi a "faca de cozinha", variando de $28,7 \%{ }^{10}$ a $72,7 \%{ }^{23}$, com média de $44,2 \%$ em doze estudos ${ }^{9,10,20,21,23,25-31}$. Os casos de homicídios por espancamento variaram de $13,0 \%{ }^{25}$ a $44,6 \%{ }^{27}$, com média de $29,5 \%$ em dez estudos, $10,20,21,25-28,30,31$. As mortes por armas de fogo variaram de $8,1 \%{ }^{27}$ a $68,0 \%{ }^{29}$, com média de $25,1 \%$ em nove estudos ${ }^{10,21,22,25-29,31}$.

Com relação à quantidade de vítimas e autores dos homicídios, os crimes tendem a apresentar apenas uma vítima e um autor do crime. Nos crimes com uma vítima a variação foi de $45,5 \%{ }^{24}$ a $93,4 \%{ }^{22}$, com média de $85,2 \%$ em cinco estu- $\operatorname{dos}^{10,22-24,27}$. Nos crimes com um autor, houve a variação de $45,5 \%{ }^{24}$ a $92,0 \%{ }^{26}$, com média de $72,4 \%$ em sete estudos ${ }^{9,10,22-24,26,27}$.

A confissão pelos autores dos crimes foi apresentada em dois estudos, variando de $26,4 \%{ }^{23}$ a $50,4 \%{ }^{22}$, com média de $38,4 \%$ em dois estu$\operatorname{dos}^{22,23}$.

No que diz respeito ao uso de álcool e outras drogas pelas vítimas ou autores dos crimes, o uso pelas vítimas variou de $17,9 \%{ }^{9}$ a $65,0 \%{ }^{20}$, com média de $43,7 \%$ em três estudos ${ }^{9,20,24}$. No que se refere ao uso pelos autores do crime variou de $14,9 \%{ }^{23}$ a $72,0 \%{ }^{20}$, com média de $34,9 \%$ em três estudos $^{9,20,23}$.

\section{Vítimas}

Quanto ao sexo de nascimento das vítimas, o masculino foi predominante, variando de $80,0 \%{ }^{9}$ a $100,0 \%{ }^{26}$, com média de $88,3 \%$ em oito estu$\operatorname{dos}^{9,10,21-23,26,30,31}$.

A faixa etária das vítimas, em geral, foi maior do que 35 anos, variando de $55,0 \%{ }^{21}$ a $80,5 \%{ }^{20}$. Cerca $64,8 \%$ das vítimas estavam com mais 35 
Tabela 1. Principais resultados dos estudos incluídos na revisão sistemática.

\begin{tabular}{|c|c|c|c|c|c|}
\hline Estudos & Local & Período & Crimes & Vítimas & Autores \\
\hline $\begin{array}{l}\text { (Bartlett, } \\
2007)^{\star}\end{array}$ & $\begin{array}{l}\text { Inglaterra } \\
\text { e País de } \\
\text { Gales }\end{array}$ & $\begin{array}{c}1976 \mathrm{a} \\
2001\end{array}$ & $\begin{array}{l}\text { - } 64 \% \text { ocorreram nas residências das vítimas } \\
\text { e } 16 \% \text { vias públicas } \\
\text { - } 31 \% \text { foram por espancamento; } 30 \% \\
\text { por arma branca; } 30 \% \text { foram por } \\
\text { estrangulamento, asfixia ou afogamento }\end{array}$ & $\begin{array}{l}\text { - } 54 \% \text { eram } \\
\text { homossexuais ou } \\
\text { bissexuais } \\
\text { - } 80,5 \% \text { tinham mais } \\
\text { de } 30 \text { anos, com } \\
\text { média de } 43 \text { anos } \\
\text { - } 65 \% \text { consumiram } \\
\text { álcool } \\
\text { - 53,2\% eram } \\
\text { empresários ou } \\
\text { tinham empregos } \\
\text { com cargos de } \\
\text { chefia; } 45,4 \% \text { eram } \\
\text { aposentados ou } \\
\text { pensionistas }\end{array}$ & $\begin{array}{l}\text { - } 72 \% \\
\text { consumiram } \\
\text { álcool } \\
\text { - 79,5\% estavam } \\
\text { com menos de } 30 \\
\text { anos, com média } \\
\text { de } 23 \text { anos } \\
\text { - } 78 \% \text { estavam } \\
\text { desempregados }\end{array}$ \\
\hline $\begin{array}{l}\text { (Bell \& Perry, } \\
\text { 2015) }\end{array}$ & $\begin{array}{l}\text { Flórida, } \\
\text { Estados } \\
\text { Unidos }\end{array}$ & $\begin{array}{c}1982 \mathrm{a} \\
1992\end{array}$ & $\begin{array}{l}-29,9 \% \text { usaram armas brancas; } 42,0 \% \\
\text { foram espancados e/ou estrangulados; } \\
22,4 \% \text { usaram armas de fogo }\end{array}$ & $\begin{array}{l}\text { - A idade média foi } \\
\text { de } 43,7 \text { anos }\end{array}$ & \\
\hline $\begin{array}{l}\text { (Boivin, } \\
2016)\end{array}$ & México & $\begin{array}{c}1995 a \\
2013\end{array}$ & $\begin{array}{l}\text { - } 49 \% \text { ocorreram em vias públicas ou hotéis; } \\
35 \% \text { nas residências das vítimas; } 18 \% \text { em } \\
\text { locais de prostituição } \\
\text { - 92\% das vítimas homossexuais ou } \\
\text { bissexuais foram encontradas em suas } \\
\text { residências, enquanto que as transgêneros } \\
\text { foram encontradas mortas, principalmente } \\
\text { em lugares públicos ( } 69 \% \text { ) e hotéis ( } 14 \% \text { ) } \\
\text { - As vítimas encontradas em lugares } \\
\text { públicos ( } 38 \% \text { ) e hotéis ( } 33 \% \text { ) foram mais } \\
\text { frequentemente torturadas } \\
\text { - } 33 \% \text { foram esfaqueadas; } 27 \% \text { foram } \\
\text { espancadas e torturadas; } 25 \% \text { foram } \\
\text { asfixiadas, estranguladas ou enforcadas e } 13 \% \\
\text { usaram armas de fogo } \\
\text { - 40\% dos autores eram amigos ou } \\
\text { conhecidos das vítimas } \\
\text { - 39\% das vítimas foram encontradas nuas; } \\
29 \% \text { das vítimas tinham sido torturadas } \\
\text { antes de sua morte e } 26 \% \text { foram encontradas } \\
\text { amarradas } \\
\text { - } 46 \% \text { dos corpos encontrados em locais } \\
\text { públicos e hotéis estavam nuas } \\
7 \% \text { das vítimas sofreram um estupro, } \\
\text { mutilação genital ou agressão por meio de } \\
\text { objetos introduzidos no ânus }\end{array}$ & $\begin{array}{l}\text { - 97\% eram do sexo } \\
\text { masculino } \\
\text { - } 55 \% \text { estavam com } \\
\text { mais de } 34 \text { anos e } \\
\text { a idade média das } \\
\text { vítimas igual a } 35 \\
\text { anos } \\
\text { - } 39 \% \text { eram } \\
\text { oficiais, sacerdotes, } \\
\text { profissional da arte } \\
\text { e da cultura; outros } \\
15 \% \text { eram estilistas e } \\
\text { comerciantes e } 14 \% \\
\text { eram profissionais } \\
\text { do sexo } \\
\text { - A proporção } \\
\text { de transgêneros } \\
\text { assassinadas entre } 25 \\
\text { e } 34 \text { anos foi o dobro } \\
\text { de homossexuais ou } \\
\text { bissexuais nessa faixa } \\
\text { etária }\end{array}$ & $\begin{array}{l}\text { - } 50 \% \text { estavam } \\
\text { entre } 25 \text { a } 29 \text { anos } \\
\text { e } 43 \% \text { entre } 18 \text { e } \\
24 \text { anos } \\
\text { - } 49 \% \text { eram } \\
\text { militares ou } \\
\text { ex-militares; } \\
33 \% \text { garotos } \\
\text { de programa; } \\
\text { 17\% eram } \\
\text { desempregados } \\
\text { ou estudantes } \\
\text { e } 11 \% \text { eram } \\
\text { garçons, } \\
\text { ajudantes } \\
\text { de cozinha e } \\
\text { similares }\end{array}$ \\
\hline
\end{tabular}

continua

anos de idade no momento do homicídio, como foi visto em seis estudos ${ }^{11,20,21,25,27,30}$. Dentre os estudos, houve dois ${ }^{29,32}$, no qual a faixa etária das vítimas foi menor do que 35 anos, onde as vítimas eram exclusivamente trânsgeneros ${ }^{29,32}$. A idade média das vítimas foi aproximadamente 39,6 anos, obtida de cinco estudos ${ }^{20,21,24,26,28}$.
Quanto à orientação sexual das vítimas e identidade de gênero, os gays e as mulheres trans são os mais acometidos nesse tipo de "crime de ódio". O acometimento das vítimas consideradas homossexuais ou bissexuais masculinos variou de $51,0 \%{ }^{11}$ a $74,4 \%{ }^{10}$, com média de $59,0 \%$ em quatro estudos ${ }^{10,11,20,25}$. O acomentimento de 
Tabela 1. Principais resultados dos estudos incluídos na revisão sistemática.

\begin{tabular}{|c|c|c|c|c|c|}
\hline Estudos & Local & Período & Crimes & Vítimas & Autores \\
\hline $\begin{array}{l}\text { (Carrara } \\
\text { \& Vianna, } \\
\text { 2006) }\end{array}$ & $\begin{array}{l}\text { Rio de } \\
\text { Janeiro, } \\
\text { Brasil }\end{array}$ & $\begin{array}{c}1970 \mathrm{a} \\
1990\end{array}$ & $\begin{array}{l}\text { - } 60,7 \% \text { dos homossexuais ou bissexuais } \\
\text { assassinados em suas residências foram } \\
\text { por armas brancas, asfixia ou objeto } \\
\text { contundente, sendo a maioria das vítimas } \\
\text { por "crimes de lucro" } \\
\text { - } 68 \% \text { das pessoas trans foram vitimadas em } \\
\text { vias públicas foram por arma de fogo, quase } \\
\text { todos por crimes de execução }\end{array}$ & $\begin{array}{l}\text { - A média de idade } \\
\text { foi inferior a } 35 \text { anos } \\
\text { - } 40 \% \text { eram negros } \\
\text { ou pardos }\end{array}$ & - \\
\hline $\begin{array}{l}\text { (Granados } \\
\text { \& Delgado, } \\
\text { 2008) }\end{array}$ & México & $\begin{array}{c}1995 \mathrm{a} \\
2000\end{array}$ & $\begin{array}{l}-46,7 \% \text { usaram armas brancas; } 34,2 \% \\
\text { foram espancamentos } \\
\text { - } 17,4 \% \text { foram encontradas nuas e } 11,4 \% \\
\text { encontradas amarradas }\end{array}$ & $\begin{array}{l}-95,1 \% \text { eram do } \\
\text { sexo masculino } \\
-61,6 \% \text { estavam com } \\
\text { mais de } 30 \text { anos }\end{array}$ & \\
\hline $\begin{array}{l}\text { (Gruenewald, } \\
2012)^{\star *}\end{array}$ & $\begin{array}{l}\text { Estados } \\
\text { Unidos }\end{array}$ & $\begin{array}{c}1990 \mathrm{a} \\
2008\end{array}$ & $\begin{array}{l}\text { - } 28,7 \% \text { usaram armas brancas; } 27,0 \% \\
\text { armas de fogo; } 22,1 \% \text { armas corporais e } \\
16,4 \% \text { objetos não cortantes } \\
\text { - } 65,3 \% \text { foram mortos por amigos ou } \\
\text { conhecidos } \\
\text { - 42,7\% houve múltiplos autores } \\
\text { - 7,2\% houve múltiplas vítimas }\end{array}$ & $\begin{array}{l}\text { - } 94,2 \% \text { eram do sexo } \\
\text { masculino } \\
\text { - } 74,4 \% \text { eram } \\
\text { homossexuais/ } \\
\text { bissexuais; } 13,3 \% \\
\text { eram transgêneros; } \\
8,8 \% \text { eram } \\
\text { heterossexuais e } 4,4 \% \\
\text { eram lésbicas }\end{array}$ & $\begin{array}{l}\text { - 100,0\% eram do } \\
\text { sexo masculino } \\
\text { - 73,4\% eram } \\
\text { da raça branca e } \\
18,1 \% \text { negros } \\
\text { - 25,1 anos foi a } \\
\text { média de idade }\end{array}$ \\
\hline $\begin{array}{l}\text { (Gruenewald } \\
\text { \& Kelley, } \\
2014)^{\star *}\end{array}$ & $\begin{array}{l}\text { Estados } \\
\text { Unidos }\end{array}$ & $\begin{array}{c}1990 \mathrm{a} \\
2010\end{array}$ & $\begin{array}{l}\text { - 41,2\% ocorreram nas residências das } \\
\text { vítimas } \\
\text { - 72,7\% usaram armas que não eram armas } \\
\text { de fogo } \\
\text { - 42,0\% houve múltiplos autores e } 93,4 \% \\
\text { houve uma única vítima } \\
\text { - 50,4\% dos autores admitiram que } \\
\text { escolheram as vítimas por causa de sua } \\
\text { orientação sexual ou identidade de gênero } \\
\text { - 28,1\% consistem em atos planejados de } \\
\text { violência contra membros da comunidade } \\
\text { LGBT } \\
\text { - 15,7\% dos infratores revelaram seus } \\
\text { crimes a outros } \\
\text { - 32,2\% dos casos o lucro não foi o principal } \\
\text { motivo do crime } \\
\text { - 8,3\% dos autores manipularam ou } \\
\text { mutilaram os corpos das vítimas }\end{array}$ & $\begin{array}{l}\text { - 95,0\% eram do } \\
\text { sexo masculino } \\
\text { - } 57 \% \text { das vítimas } \\
\text { eram brancas; } \\
19 \% \text { negras e } 17 \% \\
\text { hispânicas } \\
\text { - 4,1\% das vítimas } \\
\text { eram heterossexuais } \\
\text { (identidade } \\
\text { equivocada) }\end{array}$ & $\begin{array}{l}\text { - } 69,7 \% \text { eram da } \\
\text { raça branca. } \\
\text { - A idade média } \\
\text { foi } 25 \text { anos } \\
-69,3 \% \\
\text { dos autores } \\
\text { conheciam suas } \\
\text { vítimas }\end{array}$ \\
\hline (Kelley, & Estados & $1990 \mathrm{a}$ & - 42,0\% houve múltiplos autores & - 95,0\% eram do & $-24,9$ anos foi a \\
\hline 2013$)^{* *}$ & Unidos & 2010 & $\begin{array}{l}\text { - 41,2\% ocorreram nas residências das } \\
\text { vítimas } \\
\text { - 32,2\% foram "crimes de lucro" } \\
\text { - 72,7\% usaram armas brancas e outras } \\
\text { - 26,4\% declararam que o crime foi por } \\
\text { homofobia } \\
\text { - 59,3\% eram amigos ou conhecidos } \\
\text { - 50,4\% dos autores admitiram que } \\
\text { escolheram as vítimas por causa de sua } \\
\text { orientacão sexual ou identidade de gênero }\end{array}$ & $\begin{array}{l}\text { sexo masculino. } \\
\text { - } 56,5 \% \text { eram } \\
\text { brancos }\end{array}$ & $\begin{array}{l}\text { média de idade } \\
\text { dos autores } \\
\text { - } 69,7 \% \text { eram da } \\
\text { raça branca } \\
\text { - 14,9\% usaram } \\
\text { drogas ou álcool }\end{array}$ \\
\hline
\end{tabular}

transgêneros variou de $13,2 \%{ }^{10}$ a $100,0 \%{ }^{32}$, com média de $35,7 \%$ em cinco estudos ${ }^{10,11,25,26,32}$. Ainda houve assassinatos de homossexuais femini- no, que variaram de $3,0 \%{ }^{11}$ a $8,0 \%{ }^{25}$, com média de $3,5 \%$ em três estudos ${ }^{10,11,25}$. Os heterossexuais também foram vítimas de homicídios com pos- 
Tabela 1. Principais resultados dos estudos incluídos na revisão sistemática.

\begin{tabular}{|c|c|c|c|c|c|}
\hline Estudos & Local & Período & Crimes & Vítimas & Autores \\
\hline $\begin{array}{l}\text { Mercado } \\
\text { Mondragon, } \\
2009)\end{array}$ & México & $\begin{array}{c}1999 \mathrm{a} \\
2006\end{array}$ & $\begin{array}{l}\text { - 50,4\% ocorreram nas residências das } \\
\text { vítimas e } 23,4 \% \text { em vias públicas } \\
\text { - 33,6\% das vítimas foram esfaqueados; } \\
19,0 \% \text { espancados; } 13,0 \% \text { estrangulados e } \\
6,9 \% \text { por arma de fogo }\end{array}$ & $\begin{array}{l}\text { - 96,1\% eram do } \\
\text { sexo masculino } \\
\text { - } 65,8 \% \text { estavam } \\
\text { com mais de } 30 \text { anos }\end{array}$ & \\
\hline $\begin{array}{l}\text { Mott \& } \\
\text { Michels, } \\
2019)^{* * *}\end{array}$ & Brasil & 2018 & $\begin{array}{l}\text { - } 47 \% \text { eram amigos ou conhecidos das } \\
\text { vítimas } \\
-27 \% \text { dos autores foram identificados }\end{array}$ & $\begin{array}{l}\text { - } 51 \% \text { eram } \\
\text { homossexuais ou } \\
\text { bissexuais e } 42 \% \\
\text { eram pessoas trans } \\
\text { - } 64,5 \% \text { eram } \\
\text { solteiros } \\
\text { - } 63 \% \text { estavam com } \\
\text { mais de } 30 \text { anos } \\
\text { - } 64 \% \text { eram brancos } \\
\text { - } 23,9 \% \text { eram } \\
\text { professores e } 20,9 \% \\
\text { estudantes }\end{array}$ & \\
\hline $\begin{array}{l}\text { (Mouzos \& } \\
\text { Thompson, } \\
\text { 2000) }\end{array}$ & $\begin{array}{l}\text { Nova } \\
\text { Gales } \\
\text { do Sul, } \\
\text { Austrália }\end{array}$ & $\begin{array}{c}1989 \text { a } \\
1999\end{array}$ & $\begin{array}{l}\text { - 53,6\% ocorreram nos finais de semana } \\
\text { - 62,1\% ocorreram a noite ou madrugada } \\
\text { - 62,1\% foram nas residências das vítimas e } \\
31,0 \% \text { em vias públicas } \\
\text { - 54,5\% tiveram múltiplos autores com uma } \\
\text { vítima e } 45,5 \% \text { houve um autor com uma } \\
\text { vítima } \\
\text { - 90,9\% os autores eram mais novos que as } \\
\text { vítimas } \\
\text { - } 70 \% \text { envolveram espancamentos selvagens, } \\
\text { esfaqueamentos repetidos, mutilação e/ou } \\
\text { esquartejamento } \\
\text { - 52,3\% eram amigos ou conhecidos das } \\
\text { vítimas }\end{array}$ & $\begin{array}{l}\text { - } 43 \text { anos foi a média } \\
\text { de idade } \\
\text { - } 48,3 \% \text { consumiram } \\
\text { álcool } \\
\text { - } 93,1 \% \text { eram da raça } \\
\text { branca }\end{array}$ & $\begin{array}{l}\text { - 93,2\% eram do } \\
\text { sexo masculino } \\
\text { - 68,1\% estavam } \\
\text { entre } 15 \text { a } 24 \\
\text { anos, com a } \\
\text { mediana de } 20 \\
\text { anos } \\
\text { - 93,2\% eram } \\
\text { brancos } \\
\text { - } 77,3 \% \text { eram } \\
\text { solteiros } \\
\text { - } 81,8 \% \text { não } \\
\text { trabalhavam }\end{array}$ \\
\hline $\begin{array}{l}\text { (Oliveira, } \\
2012)^{\star * *}\end{array}$ & $\begin{array}{l}\text { Sergipe, } \\
\text { Brasil }\end{array}$ & $\begin{array}{c}1980 \mathrm{a} \\
2010\end{array}$ & $\begin{array}{l}\text { - } 43 \% \text { ocorreram em vias públicas e } 42 \% \\
\text { nas residências das vítimas } \\
\text { - 33\% usaram arma de fogo; } 30 \% \text { arma } \\
\text { branca; } 13 \% \text { estrangulamento; } 11 \% \\
\text { pauladas e } 9 \% \text { pedradas } \\
\text { - } 64 \% \text { identificaram o autor, sendo } 39 \% \\
\text { destes condenados pelo crime }\end{array}$ & $\begin{array}{l}\text { - } 73 \% \text { eram } \\
\text { homossexuais ou } \\
\text { bissexuais; } 19 \% \\
\text { pessoas trans e } 8 \% \\
\text { lésbicas } \\
\text { - } 68,5 \% \text { das vítimas } \\
\text { tinham } 30 \text { anos ou } \\
\text { mais } \\
\text { - } 21 \% \text { tinham ensino } \\
\text { superior }\end{array}$ & $\begin{array}{l}69 \% \text { tinham até } \\
24 \text { anos } \\
94 \% \text { estavam } \\
\text { solteiros } \\
76 \% \text { tinham } \\
\text { apenas o ensino } \\
\text { fundamental } \\
45 \% \text { eram } \\
\text { estudantes, } \\
\text { desempregados } \\
\text { ou autônomos }\end{array}$ \\
\hline
\end{tabular}

síveis motivações homofóbicas, pois estes foram identificados equivocadamente como um indivíduo LGBT, no qual esses assassinatos variaram de $4,0 \%{ }^{11}$ a $8,0 \%{ }^{10}$, com média de $4,8 \%$ em três estudos ${ }^{10,11,22}$.

Quanto à situação conjugal das vítimas, apenas um estudo descreveu que $64,5 \%{ }^{11}$ das vítimas estavam solteiras quando foram assassinadas.

A raça predominante das vítimas foi a branca, variando de $23,9 \%^{32}$ a $93,1 \%^{24}$, com média de $64,4 \%$ em sete estudos estudos ${ }^{9,11,22-24,29,32}$. A raça negra, que também inclui os "latinos"22,32 ou "pardos" ${ }^{2}$, foi a segunda mais acometida, variando de $37,0 \%{ }^{10}$ a $62,0 \%{ }^{32}$, com média de $40,5 \%$ em três estudos ${ }^{22,29,32}$.

As profissões das vítimas mais comuns encontradas nos achados foram os empresários, profissionais com cargos de chefia, oficiais, sacerdotes e professores, variando de $23,9 \%{ }^{11}$ a $71,2 \%{ }^{27}$, com média de $39,8 \%$ em quatro estudos ${ }^{11,20,21,27}$. 
Tabela 1. Principais resultados dos estudos incluídos na revisão sistemática.

\begin{tabular}{|c|c|c|c|c|c|}
\hline Estudos & Local & Período & Crimes & Vítimas & Autores \\
\hline $\begin{array}{l}\text { (Prunas et al., } \\
\text { 2015) }\end{array}$ & $\begin{array}{l}\text { Milan, } \\
\text { Itália }\end{array}$ & $\begin{array}{c}1993 \mathrm{a} \\
2012\end{array}$ & $\begin{array}{l}\text { - 38,5\% eram amigos ou conhecidos das } \\
\text { vítimas } \\
\text { - 40,0\% usaram armas brancas; } 42,0 \% \\
\text { foram espancados e/ou estrangulados; } \\
\text { 15,0\% usaram armas de fogo } \\
\text { - 92,0\% houve uma vítima com um autor }\end{array}$ & $\begin{array}{l}\text { - } 50 \% \text { foram mortos } \\
\text { em suas residências } \\
\text { e } 45 \% \text { em vias } \\
\text { públicas } \\
\text { - 100,0 eram do } \\
\text { sexo de nascimento } \\
\text { masculino } \\
\text { - A idade média foi } \\
\text { de } 33,4 \text { anos } \\
\text { - 100,0\% eram } \\
\text { pessoas trans }\end{array}$ & $\begin{array}{l}\text { - A idade média } \\
\text { foi de } 31 \text { anos }\end{array}$ \\
\hline (Stacey, 2011) & $\begin{array}{l}\text { Estados } \\
\text { Unidos }\end{array}$ & $\begin{array}{c}2000 \mathrm{a} \\
2005\end{array}$ & $\begin{array}{l}\text { - } 34,3 \% \text { ocorreram nas residências das } \\
\text { vítimas e } 26,9 \% \text { em vias públicas } \\
\text { - } 13,4 \% \text { houve múltiplas vítimas e } 18,0 \% \\
\text { múltiplos autores } \\
\text { - } 24,8 \% \text { eram amigos ou conhecidos das } \\
\text { vítimas } \\
\text { - } 17,4 \% \text { consumiram álcool ou drogas } \\
\text { - } 49 \% \text { usaram arma branca e } 33,2 \% \text { por } \\
\text { espancamento } \\
\text { - } 57,5 \% \text { ocorreram a noite }\end{array}$ & $\begin{array}{l}\text { - } 80 \% \text { eram do sexo } \\
\text { masculino } \\
\text { - } 66,9 \% \text { eram da raça } \\
\text { branca }\end{array}$ & $\begin{array}{l}\text { - 53,3\% eram da } \\
\text { raça branca } \\
\text { - A média de } \\
\text { idade foi } 20 \text { anos }\end{array}$ \\
\hline $\begin{array}{l}\text { (Tomsen, } \\
2002)^{\star}\end{array}$ & $\begin{array}{l}\text { Nova } \\
\text { Gales } \\
\text { do Sul, } \\
\text { Austrália }\end{array}$ & $\begin{array}{c}1989 \mathrm{a} \\
1999\end{array}$ & $\begin{array}{l}\text { - 43,2\% ocorreram nas residências das } \\
\text { vítimas e } 40,5 \% \text { em vias públicas } \\
44,6 \% \text { foram mortos por espancamento; } \\
29,7 \% \text { por esfaqueamento e } 8,1 \% \text { por arma } \\
\text { de fogo } \\
\text { - 37,8\% dos autores eram desconhecidos e } \\
34,8 \% \text { eram amigos ou conhecidos } \\
\text { - 54,4\% houve múltiplos autores } \\
56,8 \% \text { das vítimas eram no mínimo } 10 \text { anos } \\
\text { mais velhas que os autores }\end{array}$ & $\begin{array}{l}\text { - 79,7\% tinham mais } \\
\text { de } 30 \text { anos } \\
\text { - } 71,2 \% \text { eram } \\
\text { empresários ou } \\
\text { tinham empregos } \\
\text { com cargos de } \\
\text { chefia; } 28,8 \% \text { eram } \\
\text { aposentados ou não } \\
\text { trabalhavam }\end{array}$ & $\begin{array}{l}\text { - 95,6\% eram do } \\
\text { sexo masculino } \\
86,9 \% \text { tinham } \\
\text { menos de } 30 \text { anos } \\
40,7 \% \text { estavam } \\
\text { desempregados; } \\
33,2 \% \\
\text { trabalhavam com } \\
\text { serviços gerais; } \\
16,6 \% \text { eram } \\
\text { estudantes; } 9,5 \% \\
\text { eram garotos de } \\
\text { programa }\end{array}$ \\
\hline $\begin{array}{l}\text { (Waters et al., } \\
\text { 2016) }\end{array}$ & $\begin{array}{l}\text { Estados } \\
\text { Unidos }\end{array}$ & 2015 & - & $\begin{array}{l}\text { - } 67 \% \text { eram pessoas } \\
\text { trans } \\
-79 \% \text { estavam com } \\
\text { menos de } 35 \text { anos } \\
\text { - } 62 \% \text { eram negros } \\
\text { ou latinos }\end{array}$ & \\
\hline
\end{tabular}

"Estudos desenvolvidos com a mesma população, porém com metodologias, períodos e resultados diferentes e/ou complementares. "Estudos desenvolvidos com a mesma população, porém com metodologias, períodos e resultados diferentes e/ou complementares. "*"Estudos desenvolvidos com a mesma população, porém com metodologias, períodos e resultados diferentes e/ou complementares.

Fonte: Elaborado pelos autores.

\section{Autores}

Quanto ao gênero dos autores identificados dos crimes, os homens foram predominantes, variando de $93,2 \%{ }^{24}$ a $100,0 \%{ }^{10,26}$, com média de $97,7 \%$ em quatro estudos ${ }^{10,24,26,27}$.

A faixa etária dos autores identificados dos crimes foi geralmente menor do que 30 anos, va- riando de $65,8 \%{ }^{31}$ a $93,0 \%{ }^{21}$. Além disso, em torno de $74,9 \%$ dos autores do crime apresentaram idades menores do que 30 anos, mais especificamente em seis estudos ${ }^{20,21,24,25,27,31}$. A idade média desses autores foi de 24,1 anos, obtidas em sete estudos ${ }^{9,10,20,22-24,26}$.

A raça predominante dos autores identificados dos crimes foi a branca, variando de 53,3\% ${ }^{9}$ 
a $93,2 \%{ }^{24}$, com média de $59,1 \%$ em cinco estu$\operatorname{dos}^{9,10,22-24}$. Apenas um estudo identificou autores da raça negra, sendo igual a $18,1 \%{ }^{10}$.

As profissões dos autores identificados dos crimes mais comuns foram os estudantes, autonômos ou estavam desempregados, variando de $28,0 \%{ }^{21}$ a $90,5 \%{ }^{27}$, com média de $56,0 \%$ em cinco estudos $^{20,21,24,25,27}$. Vale ressaltar que os profissionais do sexo (garotos de programa) foram apresentados como possíveis autores dos crimes em dois estudos, variando de $9,5 \%{ }^{27}$ a $33,0 \%{ }^{21}$, com média de 25,2\% em dois estudos ${ }^{21,27}$.

De acordo com o Guidelines for Critically Appraising Studies of Prevalence or Incidence of a Health Problem ou Loney 1998, a avaliação de qualidade evidenciou que 14 estudos (85,7\%) apresentaram uma qualidade geral positiva ${ }^{9,10,20-31}$ e dois estudos $(14,3 \%)$ com qualidade geral neutra ${ }^{11,32}$, que são relatórios técnicos, porém apresentaram resultados importantes para revisão sistemática. A avaliação detalhada pode ser vista no Quadro 1.

\section{Discussão}

Acredita-se que esta revisão sistemática alcançou informações relevantes de acordo com o objetivo proposto, que foi de apresentar um perfil quantitativo dos homicídios contra LGBT internacionalmente. A revisão sistemática abrangeu dezesseis estudos, de seis países e três continentes, dando uma visibilidade para tais crimes, algo até o momento inexistente. Destaca-se a dificuldade de se comprovar que o homicídio foi causado por homofobia, pois na maioria das vezes o autor do crime não é conhecido ou não há conhecimento se a vítima se identificava como sendo LGBT. Salienta-se que não foi a finalidade deste estudo contextualizar e discutir a natureza do homicídio de LGBT no ambiente social, político e econômico. Contudo, é notável que nos países da América (Brasil, Estados Unidos e México) tais crimes são mais prevalentes em transgêneros do que em outros países, supondo que há uma "cultura de ódio" mais disseminada a esta popu-

Quadro 1. Características dos estudos incluídos na revisão sistemática de acordo com o Guideline Loney 1998.

\begin{tabular}{|c|c|c|c|c|c|c|c|c|c|}
\hline \multirow{2}{*}{ Estudos } & \multicolumn{8}{|c|}{ Questões } & \multirow{2}{*}{$\begin{array}{c}\text { Qualidade } \\
\text { Geral }\end{array}$} \\
\hline & 1 & 2 & 3 & 4 & 5 & 6 & 7 & 8 & \\
\hline (Bartlett, 2007) & $S$ & $S$ & $S$ & $\mathrm{NA}$ & $\mathrm{NA}$ & $S$ & $S$ & $S$ & Positivo \\
\hline (Bell \& Perry, 2015) & $S$ & $\mathrm{~S}$ & $S$ & $\mathrm{NA}$ & $\mathrm{NA}$ & $\mathrm{S}$ & $S$ & $S$ & Positivo \\
\hline (Boivin, 2016) & $\mathrm{S}$ & $S$ & $\mathrm{~S}$ & $\mathrm{NA}$ & $\mathrm{NA}$ & $S$ & $\mathrm{~S}$ & $\mathrm{~S}$ & Positivo \\
\hline (Carrara \& Vianna, 2006) & $S$ & $S$ & $S$ & NA & $\mathrm{NA}$ & $S$ & $S$ & $S$ & Positivo \\
\hline (Granados \& Delgado, 2008) & $\mathrm{S}$ & $\mathrm{S}$ & $S$ & $\mathrm{NA}$ & $\mathrm{NA}$ & $S$ & $S$ & $\mathrm{~S}$ & Positivo \\
\hline (Gruenewald \& Kelley, 2014) & $\mathrm{S}$ & $\mathrm{S}$ & $\mathrm{S}$ & $\mathrm{NA}$ & $\mathrm{NA}$ & $\mathrm{S}$ & $\mathrm{S}$ & $\mathrm{S}$ & Positivo \\
\hline (Gruenewald, 2012) & $S$ & $S$ & $S$ & NA & $\mathrm{NA}$ & $S$ & $S$ & $S$ & Positivo \\
\hline (Kelley, 2013) & $\mathrm{S}$ & S & $S$ & NA & NA & S & $S$ & $S$ & Positivo \\
\hline (Mercado Mondragon, 2009) & $S$ & $S$ & $S$ & NA & $\mathrm{NA}$ & $S$ & $\mathrm{~S}$ & $\mathrm{~S}$ & Positivo \\
\hline (Mott \& Michels, 2019) & $S$ & $S$ & $S$ & NA & $\mathrm{NA}$ & $S$ & $\mathrm{~N}$ & $\mathrm{~N}$ & Neutro \\
\hline (Mouzos \& Thompson, 2000) & $S$ & $S$ & $S$ & NA & NA & $S$ & $\mathrm{~S}$ & $\mathrm{~S}$ & Positivo \\
\hline (Oliveira, 2012) & $\mathrm{S}$ & $\mathrm{S}$ & $\mathrm{S}$ & $\mathrm{NA}$ & $\mathrm{NA}$ & $\mathrm{S}$ & $\mathrm{S}$ & $\mathrm{S}$ & Positivo \\
\hline (Prunas et al., 2015) & $S$ & $S$ & $S$ & $\mathrm{NA}$ & $\mathrm{NA}$ & $S$ & $S$ & $S$ & Positivo \\
\hline$($ Stacey, 2011) & $S$ & $S$ & $S$ & NA & NA & $S$ & $S$ & $S$ & Positivo \\
\hline (Tomsen, 2002) & $S$ & $\mathrm{~S}$ & S & NA & $\mathrm{NA}$ & $S$ & $\mathrm{~S}$ & $\mathrm{~S}$ & Positivo \\
\hline (Waters et al., 2016) & $S$ & $S$ & $S$ & NA & $\mathrm{NA}$ & $S$ & $\mathrm{~N}$ & $\mathrm{~N}$ & Neutro \\
\hline
\end{tabular}

QUESTÕES: 1. O delineamento do estudo e os métodos de amostragem são apropriados para responder à pergunta de pesquisa? 2. A base amostral é adequada? 3. O tamanho da amostra é adequado? 4. São usados critérios objetivos, adequados e padronizados para medir o desfecho de saúde? 5 . O desfecho de saúde é medido de uma forma não enviesada? 6. A taxa de resposta é adequada? As pessoas elegíveis que recusaram participar são descritas? 7. As estimativas de prevalência ou incidência são dadas com intervalos de confiança e detalhadas por subgrupo, quando adequado? 8. Os participantes e o contexto são descritos em detalhe e podem ser generalizados para outras situações similares?

S: Sim; N: Não; NA: Não aplicável.

Fonte: Elaborado pelos autores. 
lação ${ }^{10,11,25,26,32}$. Em relação aos gays não se pôde afirmar que há diferenças na dinâmica dos homicídios entre os países ${ }^{10,11,20,25}$.

Como características dos homicídios é mais provável que a vítima seja brutalmente espancada e torturada ou esfaqueada várias vezes até a morte com uma faca ou algum outro instrumento cortante ${ }^{9,10,20-22,24,25,27,29-31}$. Isso reforça a hipótese desses crimes estarem associados a requintes de crueldade, pois as vítimas possuem mais ferimentos do que os necessários para causar as suas mortes, ratificando "como possível crime de ódio"9,10,22,23. Em geral, são envolvidos nos crimes apenas uma vítima e um autor ${ }^{10,23,24}$. É mais provável que a vítima seja mais idosa do que o agressor, principalmente nos casos que envolvam os gays ${ }^{20,21,24,25,27}$. É mais propício que o homicídio tenha como autor um desconhecido ${ }^{9-11,21,23,24,26,27}$.

O perfil ligado aos aspectos sociodemográficos tem-se que as vítimas e os autores do crime apresentam maior probabilidade de serem da raça branca ${ }^{9-11,22}$. É mais propício que a vítima e o autor do crime sejam solteiros ${ }^{11,24,25}$. As vítimas têm maior probabilidade de possuir trabalho fixo, maior escolaridade e de pertencerem a classes mais abastadas do que o autor do crime, quando este é conhecido ${ }^{20,21,24,25,27}$. Desse modo, geralmente são provocados delitos chamados de "crimes de lucro", que são formas de violência que visam a obtenção de algum ganho material ou financeiro $^{22,23,29}$. Quando a vítima é um gay é mais possível que seja assassinada na própria residência, pois geralmente prezam por privacidade em

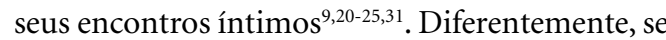
a vítima for um transgênero é mais provável ser assassinada em via pública por serem facilmente reconhecidas como LGBT e por trabalharem na rua $^{21,22}$, como profissionais do sexo. Um ponto primordial a ser discutido consiste na perda precoce das vidas desses sujeitos, que são duas vezes mais acometidas por homicídios do que os gays ${ }^{21}$ e mais de $80 \%$ dos transgêneros são assassinadas com menos de 30 anos $^{33}$, revelando as suas vidas precárias, marcadas pelos diversos tipos de vulnerabilidade, particularmente, da ausência de proteção e segurança por parte dos Estados, mesmo que esses não criminalizem as dissidências sexuais e de gênero que caracteriza a população LGBT.

Os autores dos crimes são mais propensos a pertencerem ao gênero masculino ${ }^{24}$ e possuem tendência a "ideologia machista", que trata a população de LGBT e as mulheres como "minorias desprezíveis" "3,29,34. Este fato pode explicar, de certa maneira, o tipo de postura que estes agressores assumem, provavelmente para humilhar as vítimas. É importante destacar que o uso de drogas e bebidas pelas vítimas e autores destes crimes, pode ser um fator precipitante para que eles ocorram com maior frequência e de forma mais agressiva $^{9,20,23}$.

Os pontos fortes do estudo estão em sua originalidade devido ao fato da temática ainda não haver sido estudada nesta amplitude, por meio da metodologia abrangente, cuidadosa e transparente da revisão sistemática da literatura, além da captação exaustiva de informações de diversos países e décadas diferentes, aumentando sua validade externa. Em relação às limitações, há escassez de estudos quantitativos; perda de informações pelo fato de alguns estudos detalharem pouco os seus resultados e; falta de padronização dos estudos, algo que não impediu o alcance de informações tão relevantes acerca da temática. Para solucionar tais limitações, realizou-se uma busca exaustiva nas bases de dados eletrônicas e na literatura cinzenta, o que possibilitou obter todos os estudos encontrados para inclusão no estudo.

\section{Considerações finais}

Como característica principal dos crimes, a vítima, em geral, é mais idosa do que o autor do crime, que normalmente é um desconhecido da vítima. Os transgêneros são mais acometidos do que os gays, são vítimas mais jovens e os crimes tendem a ocorrer em vias públicas. Deste modo, os homicídios da população LGBT podem ser considerados como "crimes de ódio", pois esses sujeitos, em geral, são mortos com requintes de crueldade, em que são acometidos com mais golpes e/ou tiros do que o necessário para que ocorra o óbito.

Há necessidade de pesquisas futuras para comparação e possíveis comprovações dos resultados encontrados neste estudo. Sugere-se que sejam feitos outros estudos de revisões sistemáticas para crimes não-letais; suicídios e homicídios de LGBT com foco qualitativo, algo que contribuirá no enfrentamento mais efetivo da violência e discursos de ódio, que estão tão presentes hoje em dia.

Por fim, acredita-se ter realizado um esforço analítico para melhor diagnóstico acerca dos perfis dos homicídios de LGBT no cenário internacional, que até o momento eram pouco conhecidos. Isso ocorre, principalmente, pelo fato de haver uma lacuna nos registros de tais crimes 
na maioria dos países, enfatizando aqueles em relação aos quais encontramos publicações desta revisão sistemática.

Desta maneira, pela falta de registros oficiais a respeito da violência contra LGBT, não é possível dizer qual país é o que mais mata essa população no mundo. Os dados internacionais sobre o tema servem para mostrar que existe de forma cruel e desumana a violência "LGBTfóbica", mas não são completos o suficiente, o que muitos dos autores das publicações analisadas apontam.

\section{Colaboradores}

WG Mendes trabalhou na coleta de dados, tabulação, análise descritiva e analítica, e na elaboração da metodologia. Redação do texto e padronização das normas de acordo com a revista. MJO Duarte trabalhou na coleta de dados, na revisão do texto e sugestão de partes significativas. CAF Andrade respondeu pela elaboração da metodologia, revisão do texto e sugestão de partes significativas. CMFP Silva trabalhou na revisão do texto e sugestão de partes significativas.
É nesse contexto que os estudos selecionados confirmaram que os homicídios contra LGBT podem ser considerados um grave problema de Saúde Pública mundial. Este problema envolve, em particular, a área da Saúde Coletiva, pois vêm provocando forte impacto na mortalidade desta população, ocorrendo com mais frequência na população de transgêneros, que têm perdido suas vidas precocemente. Reforçando que as estatísticas de violência de LGBT têm alcançado números crescentes e abrangido novas localidades a cada ano, o que sugere uma epidemia de homicídios.

\section{Agradecimentos}

Este artigo foi apoiado pelo Departamento de Epidemiologia e Métodos Quantitativos em Saúde, Escola Nacional de Saúde Pública Sergio Arouca, Fundação Oswaldo Cruz, Brasil.

À Fundação de Amparo à Pesquisa do Estado do Amazonas (FAPEAM) pela bolsa de doutorado concedida ao primeiro autor.

À senhora Maria de Fátima Martins, bibliotecária do ICICT/FIOCRUZ, que contribuiu na estratégia da busca sistemática nas diversas bases de dados. Ao Cientista Social Valdeci Doneda (in memoriam) pela revisão e sugestões no texto. 


\section{Referências}

1. Lombardi EL, Wilchins RA, Priesing D, Malouf D. Gender Violence: Transgender Experiences with Violence and Discrimination. J Homosex 2002; 26; 42(1):89-101.

2. Money J, Ehrhardt AA. Man and woman, boy and girl: Differentiation and dimorphism of gender identity from conception to maturity. Oxford, England: Johns Hopkins U. Press; 1972.311 p.

3. Borrillo D. Homofobia - história e crítica de um preconceito. Belo Horizonte: Autêntica; 2015. 141 p.

4. Balloni A, Sette R, editors. Handbook of Research on Trends and Issues in Crime Prevention, Rehabilitation, and Victim Support. Pennsylvania: IGI Global; 2020.

5. Osce-Odihr, editor. Combating hate crimes in the OSCE region: an overview of statistics, legislation and national initiatives. Warsaw: ODIHR; 2005. $158 \mathrm{p}$.

6. ILGA. State Sponsored Homophobia 2017: A world survey of sexual orientation laws: criminalisation, protection and recognition [Internet]. Geneva, Switzerland: International Lesbian, Gay, Bisexual, Trans and Intersex Association (ILGA); 2019. [cited 2019 Mar 30]. Available from: http://ilga.org/downloads/2017/ ILGA_State_Sponsored_Homophobia_2017_WEB. pdf

7. ILGA. Maps - Sexual orientation laws [Internet]. 2020 [cited 2019 Mar 30]. Available from: https://ilga.org/ maps-sexual-orientation-laws

8. Transgender Europe (TGEU). TMM Update Trans Day of Remembrance 2019 [Internet]. Berlin, Germany: Transgender Europe (TGEU); 2019 [cited 2019 Mar 30] p. 74. Available from: https://transrespect.org/en/ tmm-update-trans-day-of-remembrance-2018/

9. Stacey M. Distinctive Characteristics of Sexual Orientation Bias Crimes. J Interpers Violence 2011; 26(15):3013-3032.

10. Gruenewald J. Are anti-LGBT homicides in the United States unique? J Interpers Violence 2012; 27(18):36013623.

11. Mott L, Michels E. Relatório 2018: Assassinatos de LGBT no Brasil [Internet]. Brasil: Grupo Gay da Bahia - GGB; 2019 [cited 2017 May 1] p. 25. Available from: https://homofobiamata.files.wordpress.com/2017/01/ relatc3b3rio-2016-ps.pdf

12. Butler J. Vida precária: os poderes do luto e da violência. Belo Horizonte: Autêntica; 2019. 189 p.

13. Colling L, editor. Dissidências sexuais e de gênero. Salvador: Edufba; 2016. 240 p.

14. Moher D, Liberati A, Tetzlaff J, Altman DG, PRISMA G. Preferred Reporting Items for Systematic Reviews and Meta-Analyses: The PRISMA Statement. PLoS Med 2009 21; 6(7):e1000097.

15. Bettany-Saltikov J. Learning how to undertake a systematic review: part 1. Nurs Stand 2010; 24(50):47-55.

16. Khan KS, editor. Systematic reviews to support evidence-based medicine: how to review and apply findings of healthcare research. 2nd ed. London: Hodder Annold; 2011. $201 \mathrm{p}$.

17. Pellizzon RF. Pesquisa na área da saúde: 1. Base de dados DeCS (Descritores em Ciências da Saúde). Acta Cir Bras 2004; 19(2):153-163.
18. Conn VS, Valentine JC, Cooper HM, Rantz MJ. Grey Literature in Meta-Analyses. Nurs Res 2003; 52(4): 256-261.

19. Loney PL, Chambers LW, Bennett KJ, Roberts JG, Stratford PW. Critical appraisal of the health research literature: prevalence or incidence of a health problem. Chronic Dis Can 1998;19(4):170-176.

20. Bartlett P. Killing gay men, 1976-2001. Br J Criminol 2007; 47(4):573-595.

21. Boivin RR. Características y factores de la violencia homicida contra las minorías sexuales en la Ciudad de México, 1995-2013. Sex Salud Soc Rio J. 2016; (23):22-57.

22. Gruenewald J, Kelley K. Exploring Anti-LGBT Homicide by Mode of Victim Selection. Crim Justice Behav 2014; 41(9):1130-1152.

23. Kelley KK. A Mixed-Method Examination of HomicidesTargeting LGBT Individuals in the United States [these]. Arkansas: University of Arkansas; 2013.

24. Mouzos J, Thompson S. Gay-Hate Related Homicides: An Overview of Major Findings in New South Wales. Australia: Trends and Issues in Crime and Criminal Justice series; 2000.

25. Oliveira JMD. Desejo, preconceito e morte: assassinatos de LGBT em Sergipe - 1980 a 2010. [tese.] Natal Universidade Federal do Rio Grande do Norte; 2012. Prunas A, Clerici CA, Gentile G, Muccino E, Veneroni L, Zoja R. Transphobic Murders in Italy: An Overview of Homicides in Milan (Italy) in the Past Two Decades (1993-2012). J Interpers Violence 2015; 30(16):28722885.

26. Tomsen S. Victims, perpetrators and fatal scenarios: a research note on anti-homosexual male homicides. Int Rev Vict 2002; 9(3):253-271.

27. Bell JG, Perry B. Outside looking in: the community impacts of anti-lesbian, gay, and bisexual hate crime. $J$ Homosex 2015; 62(1):98-120.

28. Carrara S, Vianna ARB. "Tá lá o corpo estendido no chão...”: a violência letal contra travestis no município do Rio de Janeiro. Physis Rio J 2006; 16(2):233-249.

29. Granados JA, Delgado G. Mortality by homicide in homosexuals: characterization of the cases registered in Mexico between 1995 and 2000. Am J Forensic Med Pathol 2008; 29(1):43-48.

30. Mercado Mondragon J. Intolerance toward Sexuality Diversity and Homophobic Crimes. A Sociological Analysis. Sociologica 2009; 24(69):123-156.

31. Waters E, Jindasurat C, Wolfe C. A report from the National Coalition of Anti-Violence Programs: Lesbian, gay, bisexual, transgender, queer, and hiv-affected hate violence in 2015 - 2016 release edition [Internet]. New York, NY: Arcus Foundation; 2016 [cited 2016 Sep 11] p. 90. Available from: http://www.avp.org/storage/documents/ncavp_hvreport_2015_final.pdf

32. Mendes WG, Silva CMFP. Homicídios da População de Lésbicas, Gays, Bissexuais, Travestis, Transexuais ou Transgêneros (LGBT) no Brasil: uma Análise Espacial. Cien Saude Colet 2020; 25(5):1709-1722. 
33. Mott L. Homo-afetividade e direitos humanos. Rev Estud Fem 2006;14(2):509-521.

Artigo apresentado em 06/05/2020

Aprovado em 15/09/2020

Versão final apresentada em 17/09/2020

Editores-chefes: Romeu Gomes, Antônio Augusto Moura da Silva 